\title{
(IM) POSIBILIDAD DE ESCRIBIR EL TRAUMA. EL SILENCIO EN EL PROFUNDO $S U R$ DE ANDRÉS RIVERA
}

\section{Cristian Ignacio Vidal Barría}

\author{
Universidad de Chile \\ Chile \\ cristian.vidal.b@gmail.com \\ ORCID: 0000-0002-9423-1875
}

Fecha de recepción: 25/0I/2020 | Fecha de aceptación: 28/09/2020

\begin{abstract}
Resumen: La problemática de la escritura literaria y las posibilidades que tiene de representar la violencia y el trauma histórico es una discusión vigente tanto en los estudios filosóficos como literarios. El objetivo de este análisis es abordar estas complejidades y revisar, a través de la novela El profundo Sur (1999) del escritor argentino Andrés Rivera, las posibilidades que tiene el texto literario como dispositivo que intenta representar o figurar la violencia y el trauma en un texto ficcional. La novela toma como escenario y referencia histórica la masacre de obreros ocurrida en Buenos Aires, en el año 1919, que se ha denominado Semana Trágica. En este texto Rivera, con una propuesta estética marcada por la elipsis, elabora una reflexión sobre el lenguaje, la ficción y la reconstrucción de un hecho histórico por medio de la literatura.
\end{abstract}

Palabras claves: Literatura argentina; siglo xx; Andrés Rivera; silencio; trauma

\section{The (im) possibility of writing trauma. The silence in $\mathrm{El}$ profundo Sur by Andrés Rivera}

\begin{abstract}
The questions around literary writing and its possibilities for representing violence and historical trauma is a current discussion in both philosophical and literary studies. This article addresses these complexities and examines, through a reading of the novel El profundo Sur (1999) by Argentine writer Andrés Rivera, the possibilities of the literary text as a device that tries to represent or depict violence and trauma through a fictional narrative. The novel takes as its setting and historical reference the massacre of workers in Buenos Aires in 1919, also known as the "Semana Trágica". Rivera, whose aesthetics is marked by the use of the ellipsis, elaborates a reflection on language, fiction, and the reconstruction of a historical event through literature.
\end{abstract}

Keywords: Argentine literature; twentieth century;Andrés Rivera; silence; trauma 


\begin{abstract}
Sumário: O problema da escrita literária e suas possibilidades de representar a violência e o trauma histórico são uma discussão atual nos estudos filosóficos e literários. O objetivo desta análise é abordar tais complexidades e revisar, no romance El profundo Sur (1999) do escritor argentino Andrés Rivera, as possibilidades que o texto literário tem entanto dispositivo que procura representar ou figurar a violência e o trauma em um texto fictício. $\bigcirc$ romance toma como cenário e referência histórica o massacre de trabalhadores ocorrido em Buenos Aires, em 1919, conhecido como a "Semana Trágica". Neste texto, Rivera, com uma proposta estética marcada pela elipse, elabora uma reflexão sobre a linguagem, a ficção e a reconstrução de um fato histórico através da literatura.
\end{abstract}

Palavras-chave Literatura argentina; Século XX;Andrés Rivera; silêncio; trauma

\title{
Introducción
}

Mi obra más importante es la que no he escrito, y no la que he llevado a cabo. En mi obra escrita hay una especie de desencanto previo a la realización.

JuAn José Arreola

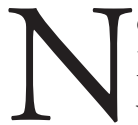

o son pocos los trabajos que se han dedicado al estudio de la narrativa de Andrés Rivera fijando su predilección en los vacíos textuales, espacios en blanco, elipsis narrativas o inscripciones del silencio. Estas denominaciones, con variantes propias de cada investigación, son distintas maneras de acercarse al estudio de la narrativa de Rivera considerando como foco central aquello no escrito o escasamente textualizado. El objetivo de este artículo es seguir un camino similar, pero desde una lectura que, por medio de reflexiones que provienen de la Filosofía y de la Literatura, sitúe el silencio en la narrativa de Andrés Rivera como una estrategia literaria que pretende figurar, mas no describir, las im-posibilidades de narrar el trauma histórico. En particular, se alude en este artículo al trauma que ha dejado la matanza de obreros ocurrida en Buenos Aires en el año 1919, conocida como la Semana Trágica, y sobre la cual Andrés Rivera compone un escenario violento y de experiencias personales a través de la subjetividad de cuatro personajes que cruzan sus vidas en una calle de Buenos Aires en aquellos convulsionados días de 1919.

La Semana Trágica, en tanto masacre de obreros de gran relevancia histórica, ha sido, desde su acontecimiento, un hecho que despertó el interés de literatos. Tal interés, y repercusión, queda en evidencia principalmente en el campo de la narrativa. Tan solo un mes después de haber acontecido la masacre, en febrero de 1919, Arturo Cancela publicó en formato folletín (en La Novela Semanal) el 
cuento "Holgorio". . El mismo cuento fue publicado tiempo después con el nombre "Una semana de holgorio" en Tres relatos porteños y tres cuentos de la ciudad (1923). David Viñas le dedica una breve ponencia al autor del cuento en el congreso de 1985, Hacia una historia de la literatura latinoamericana, con el título: "Arturo Cancela: un humorista frente al pogrom de Buenos Aires". Otra de las narrativas en que se abordó la Semana Trágica fue la novela Pesadilla (1929), de Pinie Wald. Esta novela fue publicada inicialmente en $i d i s h$ y su título original era Koshmar $^{2}$. La traducción al castellano se hizo en el año 1987 gracias al escritor Simja Sneh ${ }^{3}$. De esta novela la crítica destaca su construcción narrativa que propone una mezcla y un diálogo entre la crónica y la ficción. Dicha mixtura anticiparía técnicas y formas de literatura como la no-ficción presentes en la novela $A$ sangre fría (1966) de Truman Capote o en Operación masacre (1957) de Rodolfo Walsh. Más adelante, en 1966, David Viñas publicó la novela En la Semana Trágica. Una nueva edición de esta fue publicada en el año 2016, a propósito de los cincuenta años del libro. Después de la publicación de la novela de Viñas aparece Enero rojo, semana negra (1974), novela de Floreal Mazía. Al parecer, según las indagaciones críticas, esta novela es la de menor repercusión en los circuitos literarios. De los escasos comentarios que se han hecho de ella, en uno se dice que el autor relata "sus memorias y vivencias infantiles conservadas de aquellos días" de 1919 (Di Mario 19). Finalmente, la última novela que ha tomado como referente la Semana Trágica es El profundo Sur (1999) del escritor Andrés Rivera.

Sobre Andrés Rivera y su obra ficcional es preciso señalar una manifiesta escisión que revela dos poéticas distintas en su proyecto narrativo (Gilman 1993; Waldegaray 2000; Perilli 2010). Sus primeras novelas, El precio (1957), Los que no mueren (1959), o los libros de cuentos publicados entre 1962 y 1968, presentan -dirá Fernando Moreno (2013) - "un universo ideologizado, en el que los personajes se definen por su pertenencia de clase" (121). Este universo, entre otras características, determina la primera etapa narrativa de Andrés Rivera bajo el manto de la estética del realismo social. Además, en esta etapa, se vislumbra en las novelas "la mecánica de los poderes socioeconómicos" (Waldegaray "Historia y representación" 179) que rigen la sociedad.

Según advierte Jorgelina Núñez, la visión manifestada por Rivera en sus primeras obras cambia a raíz de "la constatación de una derrota" que deviene en

1 Señala, al respecto, María Cecilia di Mario que "las publicaciones semanales, de gran auge y circulación en la población medianamente alfabetizada en torno a los años 20 , constituyeron no sólo una de las principales ofertas culturales para los lectores medios de la época, sino también una instancia de profesionalización para jóvenes escritores ansiosos por ingresar al campo literario" (Di Mario 31).

2 Para un análisis detallado de la forma y la temática de la novela Pesadilla de Pinie Wald, véase el capítulo I del libro De crónicas y escrituras en la Semana Trágica: "Pinie Wald: cuando la pesadilla deviene crónica", de la investigadora María Cecilia Di Mario.

3 La traducción de Koshmar aparece inserta en el libro Crónicas judeo argentinas (los pioneros en idish: 1890-1944) publicado por la editorial Milá en 1987. 
leit motiv de las ficciones que escribirá después. Esta derrota supone en Rivera una desilusión en tanto que emerge de la "certeza de que la sociedad no se halla a las puertas de la revolución y que el aire equívoco de revuelta que se respira en aquellos ańos empieza a percibir los primeros signos de su fracaso" (Núnez $2001 \mathrm{~s} / \mathrm{p}$ ). Este fracaso sería uno de los motivos que provocan el cambio en el tono narrativo del autor. Existe concordancia en la crítica (Piglia; Moreno; Waldegaray) para señalar que la inflexión dentro de su proyecto literario se da con la publicación del libro de cuentos Ajuste de cuentas (1972). Sin embargo, después de esta publicación el escritor se mantendrá en silencio durante diez años. Por lo tanto, será 1982, con la publicación de Nada que perder, el momento en que se despliegue en rigor la nueva voz poética que marcará definitivamente la narrativa de Andrés Rivera. Las novelas La revolución es un sueño eterno (1987), El amigo de Baudelaire (1991), El farmer (1996) o El profundo Sur (1999), son algunas de las obras en las que autor deja al descubierto una nueva poética signada por las pocas y precisas palabras que el autor ha decidido utilizar, dicho de otro modo, una poética del silencio que puede ser leída como una gran elipsis literaria.

\section{Posibilidades de la escritura: "el libro por venir"}

La pregunta inicial que guía este artículo es sobre los avatares de la escritura literaria y la posibilidad de que a través de la ficción se pueda representar la violencia y el trauma histórico. La concepción de literatura en la que nos situamos involucra, en esta investigación, la práctica escritural y su fase previa. Esta noción es abordada en las reflexiones tardías del teórico Roland Barthes y desarrollada, con mayor detención, conforme a los preceptos filosóficos y teóricos que aporta la deconstrucción. Por lo tanto, entendemos que la literatura se da como resultado, o como un principio, que reúne dos dimensiones: una, que apunta a la intuición, y otra, a la experiencia. La intuición entendida como la capacidad de percibir algo sin intervención del raciocinio se ubicaría en una fase prelingüística, mientras que la experiencia estaría relacionada con una concepción y reflexión fenomenológica de carácter cognoscitivo. Si bien estas dimensiones no son opuestas, esto no quiere decir que sean, en un modo práctico, complementarias, o que una (intuición) anteceda a la otra (experiencia). Estas dimensiones nos abren espacio para reflexionar en torno a los procedimientos que preceden al texto escrito; vale decir, cómo emerge lo que entendemos por literatura. Para Derrida es imposible que exista lo que él llama el libro puro y afirma que para captar con "mayor proximidad la imaginación creadora, hay pues que volverse sobre lo invisible dentro de la libertad poética" (Derrida La escritura y la diferencia 16$)^{4}$. La noción de literatura pura mantiene su imposibilidad debido a que la intuición, que es uno de los principios creadores, nunca puede salir de su

4 Derrida entiende, respecto del libro puro solo "la ausencia pura -no la ausencia de esto o aquello sino la ausencia de todo, en la que se anuncia toda presencia- puede inspirar" (La escritura y la diferencia 17$)$. 
estrato prelingüístico. Si seguimos la conceptualización de Edmund Husserl, la intuición, a la que sigue un "querer decir", estaría condenada a habitar el espacio de la noesis ${ }^{5}$. Se puede encontrar una respuesta a esta condena en la deconstrucción y asumir que ese querer-decir no puede emerger, puesto que no se ajusta, y no puede enclaustrarse en palabras cuyo significado ya se encuentra prefigurado desde antes en un "campo cultural". Al respecto, Derrida afirma que "las palabras y la escritura están siempre inconfesablemente sacadas de una lectura" ( $L a$ escritura y la diferencia 245) que no permite la "potencia inaugurante" del poema venidero.

Sin embargo, que no exista literatura pura no quiere decir que no exista literatura como tal, sino al contrario. La reflexión filosófica que aquí planteamos tiene como referencia principal Le Livre à venir $(1959)^{6}$, de Maurice Blanchot, que plantea la imposibilidad primigenia de la creación poética y, por consiguiente, el emerger de un libro no escrito, no dicho. Es un libro que acompaña y acecha con palabras indecibles e indecidibles al libro que se ha escrito. En cualquier caso, solo se sabrá de ese libro, de modo aporético, en el momento en que la experiencia literaria se transforme en libro impreso; momento en que emerge un nuevo libro que se suma al gran palimpsesto que es la literatura como archivo manifestado 7 . Este libro impreso devela, en sus espacios en blanco, toda la im-posibilidad literaria y el acechar de lo que Blanchot llama El libro por venir. Dicho de otro modo, a cada libro le acompañaría un libro no textualizado que tonifica la escritura.

La novela de Rivera, El profundo Sur, surte de sentido estas reflexiones con un proyecto narrativo que constantemente se desplaza hacia aquello que permanece no-dicho. Un desconfiar de las palabras que es enunciado, en voz del narrador, por el personaje Enrique Warning: "Cuando lo invitaban a hablar, se hacía, en torno a él, el silencio [...]. Sospechaba que detrás de las palabras no había nada.

5 Si bien tomamos este concepto de la filosofía de Husserl, quien considera la noesis como el conjunto de aquellas intuiciones que habitan el pensamiento, también consideramos el concepto desde la tradición platónica bajo la cual se la define como la actividad del pensamiento ("nous") por la que se accede a un conocimiento directo e inmediato del objeto. Se opone, pues, tanto a la percepción sensible, que requiere la mediación de los sentidos, como al pensamiento discursivo ("diànoia") que recurre a la mediación del razonamiento y/o del cálculo. Para Platón la noesis representa el grado más elevado de conocimiento, al ser la única capacidad del alma que permite la captación directa de las ideas, de la verdadera realidad.

6 Citamos de la traducción al español El libro por venir (2005), de Editorial Trotta, realizada por Cristina de Peretti y Emilio Velasco.

7 Derrida advierte que la noción de "vacío como situación de la literatura" es un tema que ha inquietado a escritores tan diversos como Delacroix, Balzac, Flaubert, Valéry, Proust, T.S. Eliot, V. Woolf entre muchos otros. Pero quien lo manifiesta de un modo claro sería Antonin Artaud: "Habría que mezclar con estas voces la de Antonin Artaud, que daba menos rodeos: 'He empezado en la literatura escribiendo libros para decir que no podía escribir absolutamente nada. Cuando tenía algo que decir o escribir, mi pensamiento era lo que más me rehusaba. No tenía nunca ideas, y dos libros muy cortos, cada uno de setenta páginas, ruedan sobre esa ausencia profunda inveterada, endémica de toda idea"” (La escritura y la diferencia 17). 
O solo la desolación de los bellos gestos" (Rivera 86). La inquietud del personaje de la novela (Enrique Warning) se complementa, en cierto modo, con la propuesta estética que propone Rivera: una meta-reflexión sobre la escritura y lo nodicho tanto a nivel formal (escasez de palabras) como a nivel discursivo (diálogos o discursos de los personajes). Al respecto, Olga Tiberi (2014) afirma, además, que la obra de Rivera "quiebra el orden lógico de la prosa e insiste en una suerte de silenciamiento en el que el acto de lectura debe abismarse para constituirse en tal acción, como si solamente el azar pudiera vencer la violencia de aquello que no puede decirse" (16).

Junto a las reflexiones de Blanchot y de Derrida respecto del campo creativo y la escritura literaria, y en el contexto de la novela de Andrés Rivera, de su poética del silencio y del hecho histórico trágico al que refiere, podemos añadir una complejidad mayor y necesaria para el presente análisis. Frente a hechos históricos traumáticos, como una matanza de trabajadores, se volvería imposible, inclusive, poder textualizar y representar el acontecimiento por medio de la escritura literaria debido a que su carácter "tremendo" o catastrófico lo tornaría irrepresentable. Por lo tanto, si en un comienzo lo intuido se ve coartado de salir de su lugar, porque se niega y prácticamente no puede entrar en un signo/ significante, frente a un evento traumático la experiencia también carece de palabras que condensen o logren asir el sentido de lo que se quiere narrar y, por ende, que puedan expresar o representar tales hechos. El libro impreso, entonces, se verá nuevamente acechado, doblemente acechado, por el libro que siempre está por venir y por la experiencia que no ha podido ingresar en el texto debido a la imposibilidad de representación que genera la catástrofe, en este caso la matanza de trabajadores metalúrgicos en 1919. La novela de Andrés Rivera se torna elocuente bajo estas reflexiones y complejidades sobre la escritura. Primero, porque como a todo libro lo acecharía esa palabra venidera que no puede ser textualizada (el libro por venir), y, por otro lado, porque en sus vacíos textuales se condensa la irrepresentabilidad de la masacre.

Bajo esta lectura, El profundo Sur concentra toda esta problemática debido a que la novela abunda en vacíos textuales que no son azarosos. Por el contrario, los vacíos se tornan elocuentes al relacionarlos con un relato desafiante que -al decir de Tiberi- "pretende hacer claudicar la palabra en su puro querer-decir" $(\mathrm{s} / \mathrm{p})$. Adquiere sentido, entonces, hablar de la ruptura del orden lógico en la prosa y del silenciamiento textual en la obra de Rivera en tanto que establece un contradiscurso histórico que se ubica del lado opuesto al de la narratividad de la historia. Por su parte, Marta Waldegaray advierte lo siguiente en relación con los recursos sintácticos y tipográficos de la novela:

[su] objetivo es romper la estructura tradicional de la prosa narrativa, recursos que poseen efectos metaliterarios, puesto que a menudo los textos de Rivera, al poner en escena el acto de escribir, problematizan la condición de posibilidad de toda representación (Historia y brevedad 174). 


\section{La experiencia / lo irrepresentable}

Se señaló en el apartado anterior que solo a través del texto, o de la obra manifestada, se devela la im-posibilidad poética de un libro que siempre está por venir. La novela El profundo Sur (1999) constituye en este análisis la palabra escrita o impresa que puede llevar a una nueva reflexión sobre la creación. Esta nueva reflexión tiene que ver con la intuición que habita en el campo de la noesis y que, sin embargo, se une al texto por medio de una dinámica en la que una contiene a la otra, mas no se encuentran en niveles distintos. Derrida, en "La forma y el querer decir. Notas sobre la fenomenología del lenguaje", señala al respecto que "lo discursivo se relaciona con lo no-discursivo, [que] el 'estrato' lingüístico se entremezcla con el 'estrato' prelingüístico" (Márgenes de la filosofía 199). Este estrato prelingüístico sería, en definitiva, ese "querer decir" que no es parte de la experiencia como tal y que emerge, en el texto manifestado, como la palabra que siempre acecha y que vendrá.

Desde una perspectiva específicamente literaria, las reflexiones que hasta ahora hemos presentado condicen con toda la tradición teórico-literaria de la estética de la recepción, que es inaugurada a partir del pensamiento de Gadamer, y que se ubica en el espacio del texto, pero sin dejar de lado la figura de un sujeto que escribe y, principalmente, de un sujeto que lee y que se acerca al texto bajo determinados horizontes de expectativas. Todo texto presenta zonas de indeterminación donde se halla "lo no dicho"; en tales zonas el acto de decodificación, que debe realizar el lector, "agujerea" el acto de escritura. Son ausencias y vacíos que el lenguaje apenas alcanza a cubrir y que "requieren un lector que no retroceda ante los silencios. Lo que Rivera denomina, sin abundar demasiado, un "lector inteligente" (Orosz $2001 \mathrm{~s} / \mathrm{p}$ ). Valga la insistencia en que son palabras indecibles, que habitan un espacio prelingüístico irreductible a una experiencia en particular, lo que -según apunta Jorgelina Núñez (2001) a propósito de esta novela- habla de la "desconfianza [de Andrés Rivera] en el lenguaje, en el carácter provisorio de la enunciación y su efímera eficacia" como representación totalizante de un hecho histórico. Tal apreciación puede entenderse, dentro del marco ficcional, en el discurso de uno de los personajes de la novela cuando comenta sobre los libros que había leído: "Eso estaba escrito en los intersticios, en los blancos, en el código que fue utilizado para redactar los libros que leyó" (77). Sin embargo, no se trata de que Andrés Rivera, en su condición de "autor", establezca de manera pasiva un discurso o una reflexión sobre la escritura, el lenguaje y la representación de un hecho histórico. Es más bien la construcción de un texto y un mundo ficcional

8 La noción de "autor" a la que nos referimos es a la que Roland Barthes, en "La muerte del autor" (1987), alude como "el cuerpo que escribe" o "la persona del autor". En dicho texto Barthes elabora unas reflexiones que nos indican que la escritura es la "destrucción de toda voz, de todo origen [...] donde acaba de perderse toda identidad, comenzando por la propia identidad del cuerpo que escribe" (Barthes 65). Entendemos que la tesis de Barthes relega la figura del "autor" en tanto "nombre" o "identidad" de quien ha escrito el texto. Sin embargo, entiende, de manera lógica, que existe un sujeto que escribe. 
que articula de manera autónoma dichas reflexiones y que revela ciertas inquietudes de un sujeto que ha escrito el texto. Pese a ello, el texto y el discurso que evoca prescinden de coincidir con el pensamiento del autor.

En el caso de la novela de Andrés Rivera, el tema central es el relato y subjetivación de cuatro personajes que por azar se cruzan en una esquina de Buenos Aires. Estos personajes, por medio de la evocación, despliegan un mundo de vivencias trágicas que antecede el hecho histórico en el que están inmersos y revela la existencia de la violencia y del poder en sus distintas variantes (violencia personal y familiar, violencia social, violencia patriarcal y violencia estatal). El anclaje referencial -la Semana Trágica- resulta fundamental para proveer un mundo narrativo signado por la violencia y el poder estatal. En este caso, además, el libro no emerge de una experiencia traumática directa ${ }^{9}$, es decir, su autor no participó de la huelga, ni fue víctima de la masacre. La experiencia del autor se origina a partir de las huellas que ha dejado una voz experiencial colectiva, la de aquellos que no permitieron que este acontecimiento cayera en el olvido estarciendo la memoria a través de la escritura. Un ejemplo de ello puede ser la revisión que hicimos en el inicio de este artículo, donde rastreamos las distintas escrituras que surgieron a propósito de la Semana Trágica.

En cuanto a la experiencia, hemos identificado dos tipos: una poética y otra "vivencial", que puede ser traumática. Entendemos esta última a partir de la noción que elabora Walter Benjamin (1993). Para el crítico alemán la experiencia se desplaza desde su particularidad y -añade Di Pego interpretando a Benjamin-"del plano epistemológico-cognoscitivo para concebirla como un fenómeno social y político vinculado a la narración" (Di Pego 2). Esta experiencia vital, al ser desplazada de lo particular a lo social, guardaría la capacidad de generar estructuras de sentido. En la interacción de la experiencia vital con la experiencia poética emerge el libro que, como hemos insistido, es acechado por esa intuición metafísica que descansa en el campo noésico. Resulta interesante ańadir, por otro lado, la idea de "experiencia del presente" que plantea el crítico literario Raymond Williams, pues nos encontramos en un espacio en que existe un sujeto que lee siempre desde el presente y que es acechado, en la lectura, por el "querer decir". Pero no simplemente es acechado, sino que es solo a través de este libro impreso que se puede develar la existencia de otro libro que -siguiendo a Blanchot-siempre está por venir. Además, y lo más importante, es que sería este, el lector en el presente acechado por un libro no escrito, el receptor de nuevas experiencias poéticas que permitan generar nuevas estructuras de sentido. Supongamos que ahí reside una parte de la fuerza que tiene el texto literario, tanto en su decir como en su querer decir.

9 En la entrevista "Con Andrés Rivera. La violencia, el azar y la literatura", publicada en Revista de Libreros (1998) y rescatada por Tiberi en su artículo del año 2014, el autor afirma que la novela El profundo Sur es una de las pocas, si acaso no es la única, en que no refleja ninguna experiencia de su vida personal: "esta es la primera novela que escribo que no tiene ningún rasgo autobiográfico. Recibí, sí, una información oral de lo que fueron aquellos hechos. Y apelé, también, a mis recuerdos. Finalmente soy un hombre de setenta años" (22). 
Si nos situamos desde la experiencia del sujeto que lee, el relato no sería, en el caso de la novela El profundo Sur, la narración de un acontecimiento (histórico en este caso), "sino el acontecimiento mismo, [o] el aproximarse de ese acontecimiento" (Blanchot 27). Tal aproximación es posible por la conjunción de experiencias del autor (experiencia poética y vital devenida en libro) que se fusionan con la experiencia de un sujeto que lee en el presente. Añadimos que "los blancos" de ese libro no pueden ser significados por ser la evocación del trauma imposible de decir o por la imposibilidad misma del lenguaje. En definitiva, serían el libro impreso, los espacios en blanco de ese libro y el no-texto (intuición) los tres elementos que permiten que el acto literario que ha supuesto la creación adquiera fuerza y virtualidad para actuar, por ejemplo, sobre una historia que no da cabida monumental a una masacre de trabajadores metalúrgicos en la Argentina. Por otro lado, esta tríada de elementos presentes (o no presentes) nos llevan, en el caso de El profundo Sur, a la espera inminente y eterna, no tan solo de un libro que vendrá, sino de la develación de violencia que plantea la novela. El profundo Sur sería, entonces, antes que la narración misma, una posibilidad abierta a un estado excepcional de la historia -el verdadero estado de excepción, diría Benjamin-, que emerge a través de lo no dicho. En consecuencia, el texto no se limitaría a ser el relato de la violencia, sino el discurso y la escritura, lo dicho y lo no dicho de la violencia misma y sus posibilidades de representación. Es una intencionalidad que "de manera artesanal, cincela tiempo, espacio e historia en figuras fantasmales, en espectros que abriendo el intersticio entre lo posible y lo imposible asedian toda pretensión de cierre ontológico" (Tiberi s/p) de la historia. Tiberi, en la siguiente cita, desarrolla y complementa esta idea a través de la novela:

Roberto Bertini, el único de los cuatro personajes que se ubica del lado de la injusticia, lleva a cabo una serie de acciones que van más allá de su propia voluntad, como si un oscuro poder -confluencia de azar y violencia- suplantara su albedrío y decidiera por él. En consecuencia, uno y otro término toman el relevo del matiz existencial de los personajes y de la ocurrencia de una historia venidera. Constituyen, en la economía del relato riveriano, aquellos acontecimientos que necesariamente deben ocurrir a modo de interrupciones, en tanto únicas oportunidades para provocar un cambio de 'mundo' (s/p, cursiva nuestra).

\section{Ética y estética: doble elipsis literaria}

La interrogante inicial se preguntaba sobre la forma de representar la masacre. Sin reconocer aún su factibilidad, podemos afirmar que en el caso de El profundo Sur esto se intenta por medio de la elipsis. La elipsis narrativa en la novela de Rivera es doble. Las investigaciones que se ocupan de esta (Moreno 2013; Waldegaray 2015; Arancet 2015), priorizan una de ellas: la textual. Es decir, se ocupan de los vacíos escriturales considerando y desentrañando su eficacia estética como estrategia y recurso literario. Un ejemplo de ello puede ser la revisión que María Amelia Arancet desarrolla en su artículo "El silencio en El farmer de Andrés Rive- 
ra" (2015), en el que señala lo siguiente: "además de que el silencio está en el uso abundante y lírico del blanco de la página, también es apuntalado por el empleo de oraciones cortas y tajantes, casi diría de "mínimas frases acabadas" (sujeto- verboobjeto) que constituyen un párrafo entero" (Arancet 157). Estos análisis sin duda abren un espacio de reflexión en torno al acto escritural desde una mirada que permite rastrear la propuesta estética del autor. No obstante, como hemos venido exponiendo, nuestro análisis se sitúa en la elipsis, o vacío textual, desde una reflexión filosófica que considera el espacio en blanco como una elipsis ética, discursiva, que habla de imposibilidades de escribir lo sublime de la historia o de clausurar aquello "que no puede sino denunciar los límites que la inscripción va a atravesar" (Tiberi 1). Un silencio que es condensación (y condenación) devenido en "presencia por ausencia". Una escritura fragmentaria que "impugna la enunciación positiva" y rechaza "la palabra como revelación sintética de la realidad" (Tiberi 8).

No se trata en ningún caso de restarle mérito a los análisis antes mencionados. Lo que se propone en este artículo es una lectura complementaria, capaz de exhibir que la elipsis narrativa junto con establecer una forma de escritura violenta, siempre en suspenso, es capaz de proyectar el horizonte ético que subyace en la novela. Además, establece las complejidades que supone representar y escribir la muerte en su dimensión particular y universal. También es necesario desechar, como advirtiera Beatriz Sarlo, que el uso de la elipsis, el símbolo o la figuración supone un método para surtir la censura en la que estuvo sumida el país entre 1976 y 1981 y que ha sido heredado por los escritores contemporáneos. Es, más bien, una forma de "agudizar la incertidumbre y desestabilizar cierta banalización del recuerdo" (Waldegaray "Andrés Rivera: la ética" 223), procurando no caer en lo que, en palabras de Todorov, se entiende como "abuso de la memoria". $\mathrm{Al}$ respecto. conviene establecer un contrapunto y matizar la propuesta que aquí hacemos con una de las tesis que esboza Marta Waldegaray en las últimas hojas de su libro dedicado a la narrativa del argentino. La investigadora señala la posibilidad de que el camino de Rivera, a través de sus silencios, no sea el de escribir el trauma, sino el de la desesperanza de lo que no ocurrió y que no existió:

En el caso de Rivera, el silencio, la negatividad de su escritura (siempre frenada, resistente, que tira para atrás y poco para adelante), la puesta en escena de la destitución del ideal de completud a través de la fragmentación narrativa y tipográfica, del libro siempre inconcluso, parecen relacionarse más con lo que no ocurrió (la revolución verdadera), con lo que no tuvo lugar (los ideales del proletariado), que con el traumatismo por lo ocurrido (la violencia histórica) (Waldegaray Historia y brevedad 250).

La noción de Waldegaray es coherente con la configuración del mundo ficcional en las novelas de Rivera, pues en ella propone un nuevo camino de interpretación del silencio. No obstante, la desesperanza por aquello que no ocurrió sería un factor que suplementa el traumatismo. En El profundo Sur el sustrato primigenio de la obra es la violencia personal e histórica que determina el destino de cada personaje y su azar. Es esa disposición, reafirmada por 
las marcas textuales, la que revela el proyecto discursivo y escritural que nos propone el autor.

En definitiva, y recapitulando, hemos querido demostrar que la literatura -como hemos decidido denominar el espectro que reúne el proceso de creación y su posterior manifestación escrita, ya sea verso, prosa o diálogo- se ubica en una zona que despliega y deja ver su im-posibilidad. Una imposibilidad que, sin embargo, expande todas las posibilidades para que la escritura literaria acontezca sobre todo ahí donde existe lo irrepresentable. Por consiguiente, será solo a través de la palabra impresa que se revelará el espacio donde lo poético es lo escrito. Pero junto con ser lo escrito será la in-experiencia, intuiciones, presencias emergentes o pre-emergentes que "no necesitan esperar una definición, una clasificación o una racionalización antes de ejercer presiones palpables y de establecer límites efectivos sobre la experiencia y sobre la acción" (Williams 174). En otras palabras, es el querer decir que acecha y se imbrica con el texto escrito. Por lo tanto, se despliega en la literatura toda la posibilidad poética dicha y no dicha, experiencia e inexperiencia, decir y querer decir, que abre espacios excepcionales en estadios concretos y metafísicos. Además, como en el caso de la matanza en la Semana Trágica, la obra literaria que emerge a partir de esta se cristaliza como un archivo contrahegemónico que busca develar las perpetuaciones de la violencia y las heridas que guarda un determinado hecho histórico. Al respecto, compartimos la lectura que Tiberi desarrolla sobre Andrés Rivera, en la que afirma que "el silencio no es causa; sólo un efecto de la herida de la vida; ni siquiera es una fuerza, sino solamente una cicatriz; es un silencio indeterminado, inalterable e irrepetible que únicamente puede ser extendido cada vez que se inicia un relato" (Tiberi 5).

\section{¿Es posible representar el horror?}

Fernando Reati, en su ensayo sobre la posibilidad de Nombrar lo innombrable (1992), afirma que tanto en la literatura de la Primera Guerra Mundial como en la del Holocausto, en la novela de la Revolución Mexicana como en la de la Violencia en Colombia o en la de la Guerra Sucia en la Argentina y, añadimos por nuestra parte, en la de las Masacres de Obreros, los escritores han padecido la necesidad de referir lo atroz, lo increíble. El camino que en este análisis hemos emprendido se inicia desde la imposibilidad de una literatura pura que, paradójicamente, permite la existencia de la literatura o del libro. En esa misma línea hemos establecido la irrepresentabilidad de lo atroz, lo que en ningún caso quiere expresar la inexistencia de obras literarias que trabajen sobre aquello que Reati nombra como increíble. Por el contrario, se trata de la capacidad para asir, referir, representar o inscribir el acontecimiento en el texto. Emerge aquí la novela El profundo Sur proponiendo una manera de representar el horror, sin que con ello afirme que esto sea eventualmente posible. La aproximación de Rivera a esta problemática se da a través de lo que aquí identificamos como una doble elipsis: narrativa y discursiva, un silencio 
elocuente que entreteje, junto con lo textual, un relato y un acercamiento a la posibilidad de representar la muerte que acaeció en la Semana Trágica.

Andrés Rivera a través de su proyecto narrativo demuestra ser un escritor comprometido política y socialmente. El entramado de su escritura deja traslucir sus propias convicciones literarias a través de los personajes y del mundo ficcional de cada novela. Es Jean Dupuy quien confirma el compromiso escritural que asume Rivera. Dupuy, en cuanto alteridad de Rivera, desecha la concepción del arte por el arte, proveniente del idealismo alemán. Por su parte, el personaje Eduardo Pizarro afirma que "la poesía adquiría, pese a ella misma, un valor social que nada podía sustituir cuando tomaba la palabra en tiempos de catástrofe. Pero cuando los hombres aceptan sus propias cobardías, la poesía debe callar" (49).

Podemos afirmar, sin duda, que el interés de Rivera por la historia, y por la violencia que subyace en ella, es el material predilecto de sus ficciones, en particular de la que aquí analizamos. Por otro lado, su cuidadoso lenguaje y los recursos literarios de los que se vale permiten desvincularlo, a pesar de la referencialidad histórica, de un realismo narrativo anquilosado. Así, Rivera sale libre de juicios, salvo de los de quienes ven en su brevedad un defecto antes que un acierto. Pero, pese a esta última crítica, la brevedad narrativa, la elipsis textual, el silencio y las páginas en blanco, cuando forman parte del dilema de la irrepresentabilidad, anclado en un deber ético, evaden incluso las críticas que puedan considerar elitista una lectura como la que aquí hacemos con respecto al campo creativo del autor.

Recordemos una de las sentencias derridianas que podría ser foco de una crítica como la señalada: "El acontecimiento permanece a la vez en y sobre el lenguaje, y por ende adentro y en la superficie, una superficie abierta, expuesta, inmediatamente desbordada, fuera de sí misma" (La escritura 50). Lo que señala Derrida con estas palabras es que la historia (historiografía) es lenguaje y narración. Sin embargo, son interesantes las últimas palabras donde advierte que, a pesar de todo, el acontecimiento desborda inmediatamente el lenguaje. Quedarse con la primera parte del enunciado sería darle la espalda al compromiso riveriano en tanto que bastaría que uno de sus personajes, Jean Dupuy por ejemplo, nos dijera que mientras se reflexiona sobre el lenguaje y la imposibilidad literaria, acontece una nueva matanza de obreros en algún país latinoamericano. Es por lo dicho anteriormente que en estas reflexiones el camino comienza en la im-posibilidad de la literatura, para abrir otro campo de discusión respecto de la factibilidad y de las formas de representación y con ello desembocar en una de las diversas maneras narrativas de representar el trauma: la del silencio en la prosa de Andrés Rivera. Dicha manera acierta en poner como centro de la reflexión, en su dimensión textual, la historia, la violencia, el poder y la tragedia humana. Por otro lado, en lo no-dicho acierta al problematizar la representación de la masacre y el trauma histórico a través de la escritura; incluso se configura como discurso que cuestiona la forma realista de la novela.

Con todo lo dicho, y para finalizar, retomamos uno de los cuestionamientos que Fernando Reati esboza en su libro; no para dar una posible respuesta, sino para 
perpetuar la duda: ¿̨es posible representar el horror? Más allá de la posibilidad de representar el trauma, la inquietud debería ser, primero, sobre las formas en que se ha querido representar. Seńalamos lo anterior porque no se puede eludir aquello que es evidente, y que sustenta esta investigación: la existencia de novelas que vuelven a las masacres de obreros para traer al presente narrativo el acontecimiento. Para concluir, resulta útil volver a una de las afirmaciones de Reati que resitúa la problemática de la representación y que es válida para la novela El profundo Sur. La búsqueda que mantendrían ciertos escritores en la Argentina es respecto de la posibilidad de representación, y a ello se han dado, pero sin tener certeza de cuál sería el modo. Pese a ello, la mayoría coincide en una cosa: en la imposibilidad de representación del trauma por medio de la "simulación mimética del realismo", y en ello la novela a la que en este artículo hemos hecho referencia fundamenta la conclusión. Si bien no hemos respondido acerca de la posibilidad efectiva de representar el trauma y la violencia, al menos hemos advertido que algunos escritores argentinos han encontrado una imposibilidad: la de representación del trauma en la escritura mimética.

\section{Referencias bibliográficas}

Arancet Ruda, María Amelia. "El silencio en El farmer, de Andrés Rivera". Revista de Filosofia y Letras, vol. 68, 2015, pp. 152-66.

Barthes, Roland. El susurro del lenguaje: más allá de la palabra y la escritura. Barcelona, Paidós, 1987.

Benjamin, Walter. "Experiencia y pobreza". Discursos interrumpidos I, Madrid, Taurus, 1998, pp. 165-173.

. El narrador. Traducido por Pablo Oyarzún, Santiago de Chile, Metales Pesados, 2008.

Blanchot, Maurice. El libro por venir. Traducido por Emilio Velasco y Cristina de Peretti, Madrid, Editorial Trotta, 2005.

Derrida, Jacques. La escritura y la diferencia. Barcelona, Anthropos, 2012.

Márgenes de la filosofía, traducido por Carmen González Marín. Madrid, Cátedra, 2010.

Di Mario, María Cecilia. De crónicas y escrituras en la Semana Trágica. Buenos Aires, Ediciones del Centro Cultural de la Cooperación "Floreal Gorini", 2008.

Di Pego, Anabella. "La experiencia en Walter Benjamin. Entre el 'orden profano' y la 'intensidad mesiánica". X Jornadas de Investigación en Filosofía. Ensenada, Argentina, agosto 19-21, 2015, <http://www.memoria.fahce.unlp.edu. ar/trab_eventos/ev.7597/ev.7597.pdf>

Husserl, Edmund, César Moreno y Javier San Martín Sala. Problemas fundamentales de la fenomenología. Madrid, Alianza, 1994. 
Moreno, Fernando. "Violencia y escritura en la obra de Andrés Rivera". Memorias en Tinta. Ensayos sobre la representación de la violencia politica en Argentina, Chile y Perú, editado por Lucero de Vivanco, Santiago de Chile, Ediciones Universidad Alberto Hurtado, 2013, pp. 120-35.

Núńez, Jorgelina. "El silencio de todas las derrotas". Revista N Clarín, [Buenos Aires, Argentina], 17 de junio 2001.

Orosz, Demian. "Andrés Rivera: Soy un hombre entre los hombres". La voz del interior online, 2001, 25 oct., 2019, <http://archivo.lavoz.com.ar/2001/0627/ suplementos/cultura/nota39680_1.htm>

Perilli, Carmen. "Reformulaciones del realismo: Bernardo Verbitsky, Andrés Rivera, Juan José Manauta, Beatriz Guido". Historia crítica de la literatura argentina. El oficio se afirma, Buenos Aires, Emecé, 2004, pp. 545-72.

Piglia, Ricardo. "De la traición a la literatura”. Los libros, n. ${ }^{\circ}$ 27, [Buenos Aires, Argentina], julio 1972, p. 26.

Reati, Fernando. Nombrar lo inmombrable: violencia politica y novela argentina: 1975-1985. Buenos Aires, Legasa, 1992.

Rivera, Andrés. El profundo Sur. Barcelona, Seix Barral, 2006.

Sarlo, Beatriz. Tiempo pasado. Cultura de la memoria y giro subjetivo. Una discusión. Buenos Aires, Siglo XXI, 2007.

Tiberi, Olga. "La narrativa de Andrés Rivera. Una lectura derridiana". Argus-a. Artes y Humanidades, vol. 3, no 13, 2014, s/p.

Vidal, Cristian. "Del espacio histórico al espacio literario: reflexiones teóricas sobre la literatura y su relación con la historia”. Dimensiones: el espacio y sus significados en la literatura hispánica, Madrid, Biblioteca Nueva, 2017, pp. 225-34.

. Matanzas fundacionales: las masacres de obreros en la "novela histórica" hispanoamericana. Tesis, Universidad Complutense de Madrid, 2019.

Wald, Pinie. Pesadilla: novela-crónica de la semana trágica (1919). Buenos Aires, Ameghino Editora, 1998.

Waldegaray, Marta Inés. "Andrés Rivera: la ética de hacer memoria". Anales de Literatura Hispanoamericana, vol. 36, 2007, pp. 221-33.

. Historia y brevedad narrativa: la escritura de Andrés Rivera. Buenos Aires, Biblos, 2015.

. "Historia y representación en la narrativa reciente de Andrés Rivera (Argentina)". América: Cahiers du CRICCAL, vol. 24, 2000, pp. 179-89, https://doi.org/10.3406/ameri.2000.1464

Williams, Raymond. Marxismo y literatura, traducido por Pablo Di Masso. Barcelona, Península, 2000. 